\title{
Influences of environmental changes on water storage variations in Central Asia
}

\author{
HU Weijie ${ }^{1,3}$, "LIU Hailong ${ }^{2}$, BAO Anming ${ }^{1}$, Attia M. El-Tantawi ${ }^{1,4}$ \\ 1. State Key Laboratory of Desert and Oasis Ecology, Xinjiang Institute of Ecology and Geography, CAS, \\ Urumqi 830011, China; \\ 2. School of Resources and Environment, University of Electronic Science and Technology of China, Chengdu \\ 611731, China; \\ 3. CAS Research Center for Ecology and Environment of Central Asia, Urumqi 830011, China; \\ 4. Institute of African Research and Studies, Cairo University, Giza 12613, Egypt
}

\begin{abstract}
The spatio-temporal pattern of the global water resource has significantly changed with climate change and intensified human activities. The regional economy and ecological environment are highly affected by terrestrial water storage (TWS), especially in arid areas. To investigate the variation of TWS and its influencing factors under changing environments, the response relationships between TWS and changing environments (climate change and human activities) in Central Asia have been analyzed based on the Gravity Recovery and Climate Experiment (GRACE) data, Climatic Research Unit (CRU) climate data and Moderate Resolution Imaging Spectroradiometer (MODIS) remote sensing data products (MOD16A2, MOD13A3 and MCD12Q1) from 2003 to 2013. The slope and Pearson correlation analysis methods were used. Results indicate that: (1) TWS in about $77 \%$ of the study area has decreased from 2003 to 2013 . The total change volume of TWS is about $2915.6 \times 10^{8} \mathrm{~m}^{3}$. The areas of decreased TWS are mainly distributed in the middle of Central Asia, while the areas of increased TWS are concentrated in the middle-altitude regions of the Kazakhstan hills and Tarim Basin. (2) TWS in about $5.91 \%$ of areas, mainly distributed in the mountain and piedmont zones, is significantly positively correlated with precipitation, while only $3.78 \%$ of areas show significant correlation between TWS and temperature. If the response time was delayed by three months, there would be a very good correlation between temperature and TWS. (3) There is a significantly positive relationship between TWS and Normalized Difference Vegetation Index (NDVI) in $13.35 \%$ of the study area. (4) The area of significantly positive correlation between TWS and evapotranspiration is about $31.87 \%$, mainly situated in mountainous areas and northwestern Kazakhstan. The reduction of regional TWS is related to precipitation more than evaporation. Increasing farmland area may explain why some areas show increasing precipitation and decreasing evapotranspiration. (5) The influences of land use on TWS are still not very clear. This study could provide scientific data useful for the estimation of changes in TWS with climate change and human activities.
\end{abstract}

Received: 2017-07-24 Accepted: 2018-01-26

Foundation: National Natural Science Foundation of China, No.51569027; No.41371419; International Partnership Program of the Chinese Academy of Sciences, No.131551KYSB20160002; Special Institute Main Service Program of the Chinese Academy of Sciences, No.TSS-2015-014-FW-1-2

Author: Hu Weijie (1990-), Research Intern, specialized in hydrology and water resources. E-mail: wjhu@ms.xjb.ac.cn "Corresponding author: Liu Hailong (1974-), Professor, specialized in hydrology and water resources. E-mail: liuhl@uestc.edu.cn 
Keywords: terrestrial water storage; Central Asia; climate change; land use

\section{Introduction}

In arid and semiarid regions where the ecological environment is extremely vulnerable, terrestrial water storage (TWS) has important influences on the regional climate change and ecological environment (Liu et al., 2013; Zhang et al., 2012). TWS changes have become one of the major limiting factors for socio-economic development (Cao et al., 2015; Long et al., 2014; Ramillien et al., 2005). Therefore, studying the spatial and temporal variations of TWS is important in informing sustainable utilization of regional water resources and sustainable socio-economic development.

TWS comprises groundwater, soil moisture, surface water bodies (lakes, rivers and reservoirs), glaciers, snow water equivalent, and canopy water storage (Syed et al., 2008). Global water storage is distributed extremely unevenly in time and space, and shows variable trends (Long et al., 2015; Schmidt et al., 2006; Yang et al., 2013). Existing studies have indicated a decreasing trend in TWS in Central and South Asia (Singh et al., 2012; Tangdamrongsub et al., 2011), of $0.42 \pm 0.12 \mathrm{~cm} \cdot \mathrm{a}^{-1}$ in the Tianshan region, China (Yang and Chen, 2015). Conversely, TWS in the Tarim River Basin shows a generally increasing trend (Yang et al., 2015). Glacier and snowmelt are the main important water resources in arid and semiarid regions in Central Asia (Sorg et al., 2012; Chen et al., 2015) where TWS was remarkably affected by climate change (Immerzeel et al., 2010; Sorg et al., 2012). In the study area, glaciers and snow are the main components of TWS as the most beginning of rivers originate from the Tianshan Mountains (Aizen et al., 1997). The results of recent researches indicated that the glacier and snow have different upward or downward tendency, glacier and snowmelt decreased TWS in the mountain and basin regions (Matsuo and Heki, 2010) but increased it in the surrounding basin area (Yang et al., 2015).

Changes in land water reserves are mainly influenced by climate change and human activities. Research shows significant correlation between water storage changes and temperature, precipitation and snow water equivalent in Central and South Asia (Tangdamrongsub et al., 2011), and the precipitation in the Amazon Basin has a close relationship with TWS change (Frappart et al., 2013). In the Tarim River Basin, rainfall, runoff and evapotranspiration are major factors affecting the water storage (Yang et al., 2015), which is consistent with the results of the Amazon Basin (Chen et al., 2009). TWS changes in 23 major basins around the world were analyzed by Syed et al. (2008), which showed that for water storage changes, evapotranspiration plays a key role in middle altitude regions while snowmelt in high altitude regions and precipitation are dominant factors in the tropical zone. Human activities also play an important role in TWS changes. For example, anthropogenic factors, El Niño-Southern Oscillation (ENSO) and precipitation affected water storage changes in the Nile Basin and Ganges River Basin (Awange et al., 2014; Khandu et al., 2016). The dominant contributor to the TWS excess was found to be intensive surface water irrigation in the middle and southeastern Yangtze River Basin (Huang et al., 2015). On a macro scale, TWS changes are significantly related to vegetation and land use in Northern Eurasia (De et al., 2015; Velicogna et al., 2015). Thus, current research mainly focuses on single climatic factors or human activities, and mostly on humid and semihumid regions, while comprehensive studies of arid areas are limited. 
TWS can be determined through in situ observations, but this is limited to small areas and partial components, such as soil moisture and snow water equivalent (Cayan, 1996; Robock et al., 2000; Serreze et al., 1999). It is more difficult to monitor water resources at large scales (Alley et al., 2002; Lettenmaier and Famiglietti, 2006). Microwave satellite sensors can provide estimates of surface (upper few $\mathrm{cm}$ ) soil moisture and only in locations where vegetation is sparse (Gao et al., 2004; Njoku et al., 2003). The accuracy of simulations using land surface models is limited by the difficulty in obtaining the required parameters (Dijk et al., 2013; Huang et al., 2015). Gravity recovery and climate experiment (GRACE) data have alleviated the shortcomings of the above methods, and could quantify the variations of terrestrial water storage from space. Previous studies have suggested that GRACE accuracy is high enough to resolve mass variations for large river basins or regions of several hundred kilometers extension (Wahr et al., 2004; Velicogna and Wahr, 2006) allowing the possibility of quantitative studies of TWS changes at large or medium scale. Until now, GRACE data have been widely used to study water storage changes (Luthcke et al., 2006; Rodell et al., 2009; Tapley et al., 2004). Many studies indicate that TWS changes estimated using GRACE data are consistent with the results simulated by hydrologic models (Han et al., 2010; Mohamed et al., 2011; Velicogna and Wahr, 2006). Thus, GRACE is an important data source for studying changes in regional water storage.

As a vulnerable ecological region, the gap between supply and demand of water in Central Asia has increased with climate change and intensified human activities in recent years (Bernauer and Siegfried, 2012; Siegfried et al., 2012). However, the studies paid little attention to the impact of climate change on regional TWS variations in Central Asia. In order to explore the relationship between water supply and demand we used GRACE data, CRU climate data and remote sensing datasets including evapotranspiration, vegetation index and land use from 2003 to 2013. Using slope and Pearson correlation analysis methods, we have investigated temporally and spatially response relationships between TWS variation and environmental change focusing on climate change and human activities in Central Asia.

\section{Study area}

The area defined as Central Asia covers five countries of the former Soviet Union (Kazakhstan, Kyrgyzstan, Tajikistan, Uzbekistan, and Turkmenistan) as well as Xinjiang, an autonomous region in northwestern China (Deng and Chen, 2016). It is largely confined within $34^{\circ} 34^{\prime}-55^{\circ} 43^{\prime} \mathrm{N}$ and $46^{\circ} 49^{\prime}-96^{\circ} 37^{\prime} \mathrm{E}$ (Figure 1) and covers about $601 \times 10^{4} \mathrm{~km}^{2}$, making up about a third of all arid areas in the world (Chen et al., 2008). Located at the center of Eurasia, far from the oceans, with a dry climate, Central Asia belongs to a typical continental climate zone. The annual mean temperature of Central Asia is $4-8^{\circ} \mathrm{C}$ (Lioubimtseva and Henebry, 2009), the annual mean precipitation is 100-400 mm (De Pauw, 2008), and the evapotranspiration is up to 900-1500 mm (Qin, 1999). Large quantities of glaciers and permanent snow form "wet islands" in arid inland mountains, and are a main recharge source of rivers and lakes in plains during the dry season. The study area has a total population of 65 million, and cultivated land, natural vegetation and water body cover $70.1 \times 10^{4} \mathrm{~km}^{2}, 313.2 \times 10^{4} \mathrm{~km}^{2}$, and $13.8 \times 10^{4} \mathrm{~km}^{2}$ of the area, respectively (Chen et al., 2013). 


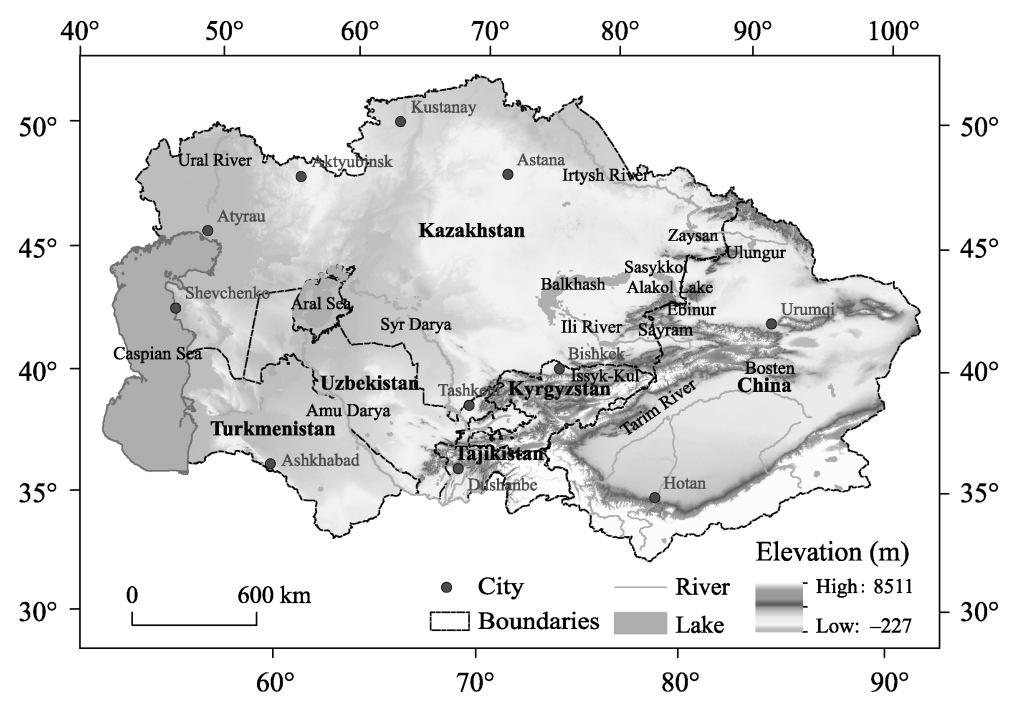

Figure 1 Study area of Central Asia

\section{Data and methods}

\subsection{Data sources}

In this study, the spatial and temporal variations of TWS in Central Asia were analyzed using GRACE (Level2 RL05 GSM) products published by the Center for Space Research (University of Texas at Austin) from January 2003 to December 2013 (http://icgem. gfz-potsdam.de/ICGEM/TimeSeries.html).

Meteorological data (2003-2013) used in this paper were produced by the Climate Research Unit (CRU TS v.3.23), University of East Anglia (http://www.cru.uea.ac.uk/cru/ data/hrg/). Evapotranspiration data (MOD16A2) were provided by the Numerical Terra dynamic Simulation Group (NTSG), University of Montana (http://www.ntsg.umt.edu/project/ mod16). The Shuttle Radar Topography Mission (SRTM) data were used as a digital elevation model. The dataset was provided by International Scientific \& Technical Data Mirror Site, Computer Network Information Center, CAS (http://datamirror.csdb.cn). Both NDVI data (MOD13A3) and Land-Use and Land-Cover Change (LUCC) data (MCD12Q1) were downloaded from the Goddard Space Flight Center, NASA (https://ladsweb.nascom.nasa. gov/data/search.html). The temporal and spatial resolutions of data used in this study were given in Table 1.

\subsection{Data processing}

The monthly spherical harmonics coefficients of GRACE gravity were converted into the equivalent water height by Matlab; then these data and the climate data (precipitation and temperature) from CRU were transformed into raster data to ana-
Table 1 Data information

\begin{tabular}{ccc}
\hline Data name & Temporal resolution & Spatial resolution \\
\hline GRACE & Monthly & $1^{\circ} \times 1^{\circ}$ \\
CRU & Monthly & $0.5^{\circ} \times 0.5^{\circ}$ \\
MOD16A2 & Monthly & $1 \mathrm{~km} \times 1 \mathrm{~km}$ \\
MOD13A3 & Monthly & $1 \mathrm{~km} \times 1 \mathrm{~km}$ \\
MCD12Q1 & Yearly & $500 \mathrm{~m} \times 500 \mathrm{~m}$ \\
DEM & & $90 \mathrm{~m} \times 90 \mathrm{~m}$ \\
\hline
\end{tabular}


lyze the TWS by ArcGIS. Filling missing data was done using mean value method, a simple and rapid method to interpolate missing data, which does not affect the estimate of the mean value. MODIS data processing (mosaicking, extracting, converting, transforming, resampling, and recoding) was dependent on the MODIS Reprojection Tool (MRT). Data analysis was achieved using ENVI 5.1 and ArcGIS10.2 provided by Environmental Systems Research Institute (ESRI), Inc.

\subsection{Calculation of TWS changes based on GRACE data}

Terrestrial water storage could be estimated according to the GRACE spherical harmonic coefficients at monthly time-scales (Wahr et al., 1998). TWS fluctuations would bring changes in gravity field. This change can be expressed by spherical harmonic coefficients. So, water density could be obtained through gravity field, and be transformed into equivalent water height. The equation of equivalent water height with gravity spherical harmonic coefficients is listed as follows (Yang and Chen, 2015):

$$
\Delta H(\theta, \phi)=\frac{2 a \rho_{a v e} \pi}{3 \rho_{W}} \sum_{l=0}^{N} \sum_{m=0}^{l} \frac{2 l+1}{1+k_{l}} W_{l} P_{l m}(\cos \theta)\left[\Delta C_{l m} \cos (m \phi)+\Delta S_{l m} \sin (m \phi)\right]
$$

where $H$ is equivalent water height, $\theta$ is the latitude, $\varphi$ is the longitude, $a$ is the equatorial radius, $\rho_{\text {ave }}$ is the mean density of the Earth, $\rho_{w}$ is the density of water, $k_{l}$ is the Loew coefficient, $C_{l m}$ and $S_{l m}$ are the coefficients of the gravity spherical harmonics coefficients (Stokes' coefficients), and $P_{l m}(\cos \theta)$ is the $l$ th degree and $m$ th order fully-normalized Legendre function, with maximum degree 1 and order $\mathrm{m}$, expanded to $60, W_{l}$ is the weight function, which can be obtained by the following recursion formula:

$$
W_{0}=\frac{1}{2 \pi}, \quad W_{1}=\frac{1}{2 \pi}\left[\frac{1+\mathrm{e}^{-2 b}}{1-\mathrm{e}^{-2 b}}-\frac{1}{b}\right], \quad W_{l+1}=-\frac{2 l+1}{b} W_{l}+W_{l-1}, \quad b=\frac{\ln 2}{1-\cos (r / a)}
$$

where $a$ is the equatorial radius, and $r$ is the Gaussian smooth radius ( $r=300 \mathrm{~km}$ in this paper).

\subsection{Slope analysis method}

In order to analyze the fluctuation characteristics of TWS, precipitation, temperature, NDVI and evapotranspiration with time, the slope analysis method was applied to calculate the changing trends. The formula used is as below (Wang et al., 2010):

$$
S l p=\frac{\mathrm{N} \sum_{i=1}^{\mathrm{N}} i X_{i}-\left(\sum_{i=1}^{\mathrm{N}} i\right)\left(\sum_{i=1}^{\mathrm{N}} X_{i}\right)}{\mathrm{N} \sum_{i=1}^{\mathrm{N}} i^{2}-\left(\sum_{i=1}^{\mathrm{N}} i\right)^{2}}
$$

where $S l p$ is the change slope, $i$ is the corresponding time for $X_{i}(i=1$, in the year of 2003), and $\mathrm{N}$ is the quantity of samples (i.e., number of years, $\mathrm{N}=11$, in this paper). If $S l p>0$, the response relationship between the variables would be a positive trend, otherwise, it would be a negative trend.

\subsection{Pearson correlation analysis method}

Climate factors, vegetation and land use affect TWS along with time and space. The vari- 
ables are assumed to be independent and continuous, and in a normal distribution, the Pearson correlation analysis method was used to discuss the close links between these variables in this study. The formula is as follows (Zhou et al., 2016):

$$
r=\frac{\mathrm{N} \sum_{i=1}^{\mathrm{N}} X_{i} Y_{i}-\sum_{i=1}^{\mathrm{N}} X_{i} \sum_{i=1}^{\mathrm{N}} Y_{i}}{\sqrt{\mathrm{N} \sum_{i=1}^{\mathrm{N}} X_{i}^{2}-\left(\sum_{i=1}^{\mathrm{N}} X_{i}\right)^{2}} \sqrt{\mathrm{N} \sum_{i=1}^{\mathrm{N}} Y_{i}^{2}-\left(\sum_{i=1}^{\mathrm{N}} Y_{i}\right)^{2}}}
$$

where $r$ is the Pearson correlation coefficient, $i$ is the corresponding time for $X_{i}$ and $Y_{i}(i=1$, in the year of 2003), and $N$ is the number of years ( $N=11$, in this paper). The coefficient $r$ ranges from -1 to 1 , and the greater the value of $|r|$, the higher the correlation. There is weak correlation when $|r|$ is less than 0.3 , low correlation when greater than 0.3 and less than 0.5 , moderate correlation when greater than 0.5 and less than 0.8 , and high correlation when greater than 0.8 (Suo et al., 2009).

\section{Results and discussion}

\subsection{Temporal and spatial variations of TWSC in Central Asia}

In order to analyze the temporal and spatial variations of the terrestrial water storage changes (TWSC) in Central Asia, the monthly and inter-annual TWSC during 2003-2013 were calculated.

\subsubsection{Temporal variations of TWSC}

Based on equation (1), the earth's surface density was calculated using spherical harmonic coefficients of gravity field. It was converted into equivalent water height, which represents TWSC. The monthly TWSC is shown in Figure 2.

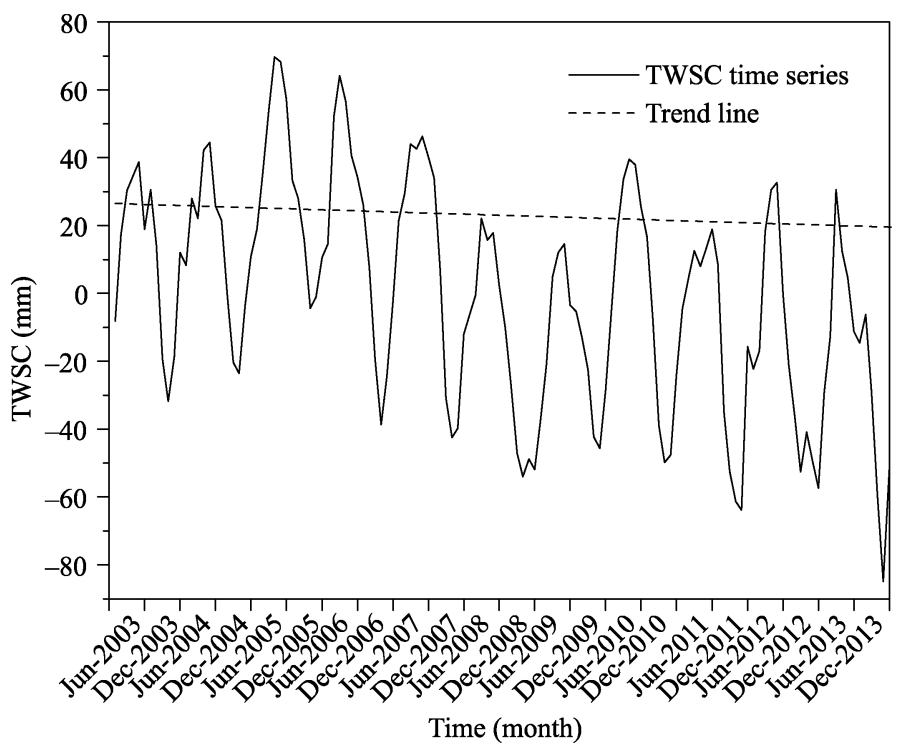

Figure 2 Temporal variations of TWS 
TWS anomalies in the GRACE dataset (Figure 2) show a decreasing trend from January 2003 to December 2013, with a slope of $-4.85 \mathrm{~mm} \cdot \mathrm{a}^{-1}$. The maximum positive anomaly of TWS of $69.61 \mathrm{~mm}$ occurred in April 2005, while the minimum negative anomaly of about $-84.90 \mathrm{~mm}$ occurred in November 2013. Before 2005, TWS increased at a rate of 5.04 $\mathrm{mm} \cdot \mathrm{a}^{-1}$, then it began to decrease. The largest decrease of $-24.24 \mathrm{~mm} \cdot \mathrm{a}^{-1}$ occurred from 2006 to 2008. Afterwards, the decreasing trend slowed down to $-5.39 \mathrm{~mm} \cdot \mathrm{a}^{-1}$. Over the whole period, the reduction of TWS in volume was $2915.6 \times 10^{8} \mathrm{~m}^{3}$.

\subsubsection{Spatial variations of TWSC}

The first monthly mean values of TWS were calculated every year. Based on the results, the inter-annual variation trend of TWS was obtained. To study the spatial variations in TWSC, the percentage change in the inter-annual variation from 2003 to 2013 compared with TWS in 2003 was computed (Figure 3).

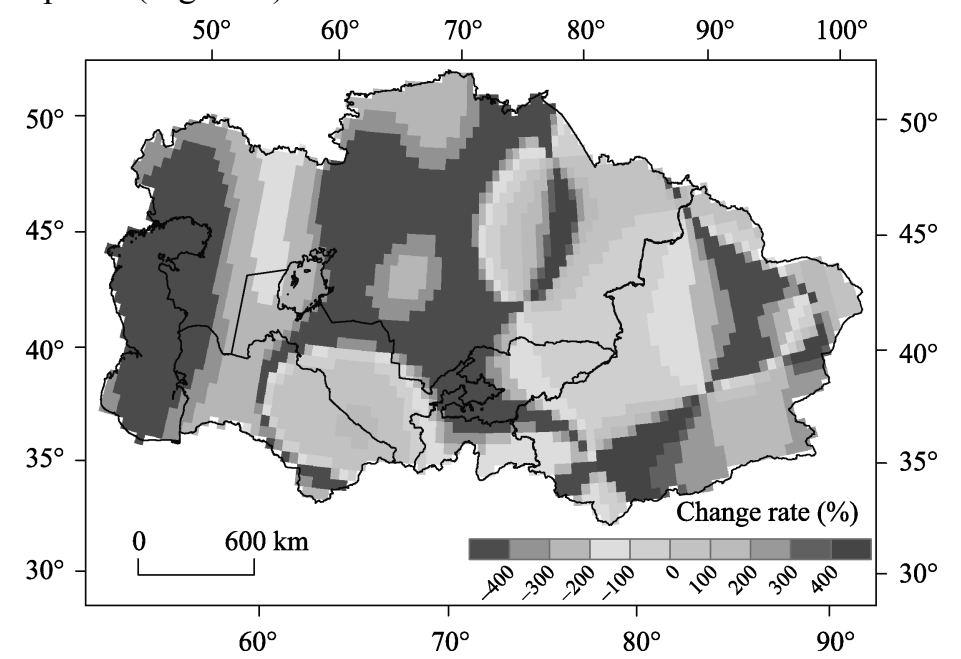

Figure 3 Spatial variations of TWS

Figure 3 shows a decreasing trend in TWS in most parts of Central Asia from 2003 to 2013, and the overall decrease in the west is larger than in the east. The TWS increases are mainly over the northeast of Turkmenistan, the southeast of Uzbekistan, east of Kazakhstan and east of Xinjiang, China. Further analysis revealed a decreasing trend in TWS in 77.04\% of Central Asia from 2003 to 2013, and the rate of decrease is more than $400 \%$ in the Caspian Sea and its coastal lowlands, the middle of the five Central Asian countries and the north of Xinjiang, China. These areas account for $41.92 \%$ of the areas where TWS decreased. While in $22.96 \%$ of Central Asia TWS increases, the rate of increase is less than $100 \%$ in $46.4 \%$ of the above regions and greater than $400 \%$ in only $13.44 \%$ of the areas in the east of Kazakhstan, the southeast of the Tarim Basin and the west of the Kunlun Mountains. TWS changes may attribute to the melting of glaciers in the upper reach of the Amu Darya River and Ili River as a result of global warming and the changes affecting the terminal lake Balkhash Lake.

TWS can be described by the water balance equation $\Delta \mathrm{W}=\mathrm{P}-\mathrm{R}-\mathrm{E}$, where $\Delta \mathrm{W}$ is terrestrial water storage, $\mathrm{P}$ is precipitation, $\mathrm{R}$ is runoff, and $\mathrm{E}$ is evapotranspiration. Vegetation has close relationship with precipitation, runoff and evapotranspiration. Temperature also greatly affects evapotranspiration. On the other hand, the human activities altered the water resource 
redistribution and the land use types. So the factors influencing the water storage variations in Central Asia, including climate change, vegetation change and human activities, are discussed in the following section.

\subsection{The influence of climate change on TWSC in Central Asia}

To study the influence of climate change on TWSC, the spatial variations of climatic factors were analyzed. The mean correlation coefficients between TWS and both climatic elements of precipitation and temperature were calculated.

\subsubsection{Fluctuation characteristics of regional climate}

Previous studies have shown that the climate in Central Asia has become warmer and more humid in recent years (Chen et al., 2011; Hu et al., 2014). Accordingly, precipitation and temperature variables were selected to analyze the effects of climate change on TWSC. The change rates of precipitation and temperature (based on the absolute value of 2003) were calculated. The spatial characteristics of climate change are shown in Figure 4.

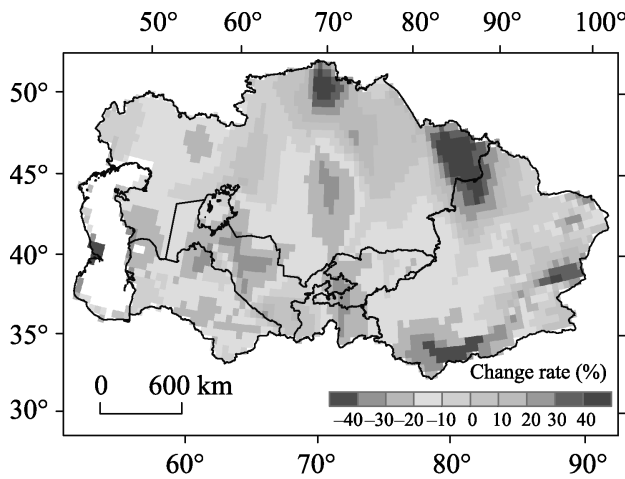

(a) Precipitation

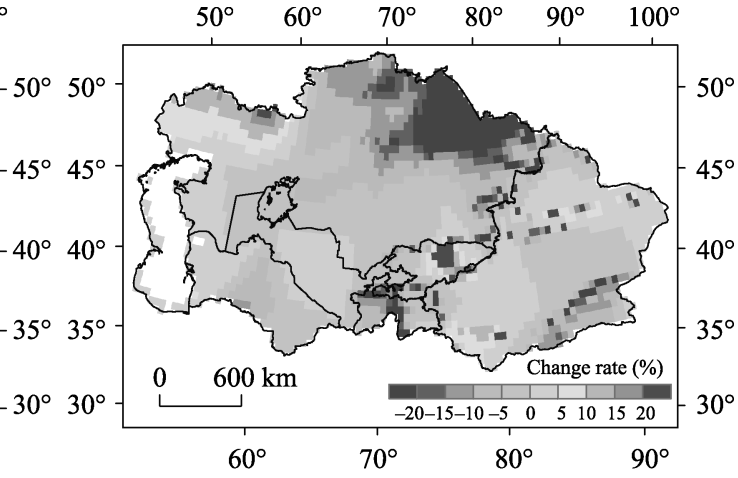

(b) Temperature

Figure 4 Spatial variations of climatic factors

Figure $4 \mathrm{a}$ indicates that precipitation increased in $72.89 \%$ and decreased in $27.11 \%$ of Central Asia. The areas where precipitation decreased are mainly distributed in the central zone of Uzbekistan, the east of Tajikistan, the west of Kyrgyzstan, south-central Kazakhstan, the south of the Tarim Basin and the west of the Kunlun Mountains. The precipitation data shows an increasing trend in northern and eastern Kazakhstan, northwestern and eastern Xinjiang, China from 2003 to 2013. Figure 4b shows a decreasing trend in temperature in about $64.71 \%$ of Central Asia from 2003 to 2013, mainly over northeastern Kazakhstan, central Tajikistan and southeastern Xinjiang. The temperature increase is below $5 \%$ in about $73.93 \%$ of the region, while the temperature increased more significantly in the northern Turgay Plateau and to the west of it, central Kyrgyzstan and sporadic areas in north-central Xinjiang.

\subsubsection{Relationship between climate change and TWSC in Central Asia}

To analyze the relationships between TWSC and climate change, the Pearson correlation analysis method was used to calculate the correlation coefficients between TWS and precipitation and temperature. Then, significance tests were carried out (significant when $P<0.05$; extremely significant when $P<0.01$ ). The results are shown in Figures 5 and 6 . 


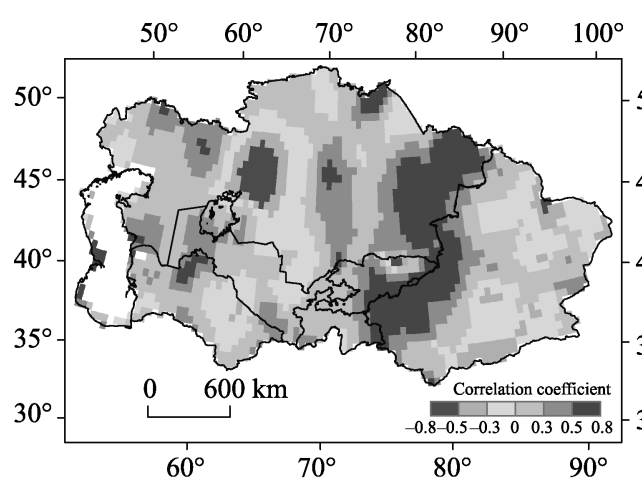

(a) Correlation coefficients

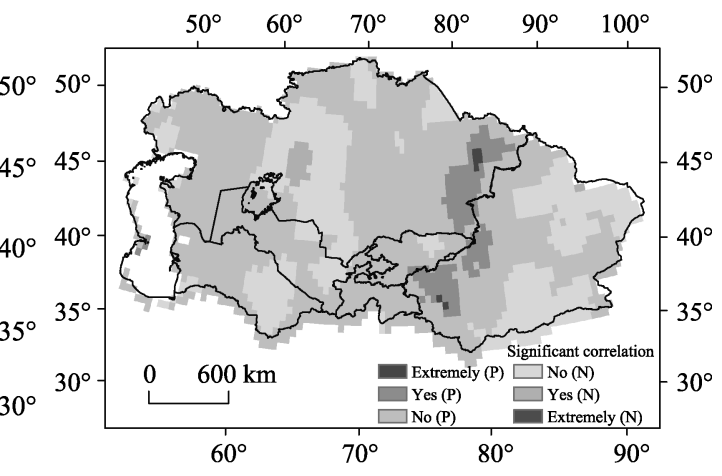

(b) Results of significance test

Figure 5 Response relationship between TWS and precipitation

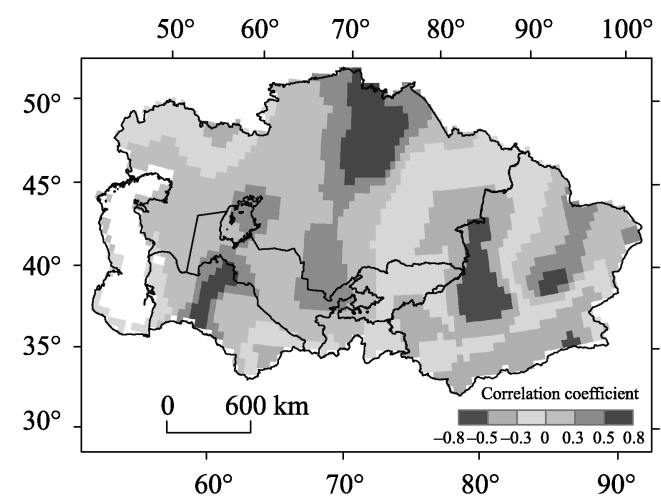

(a) Correlation coefficients

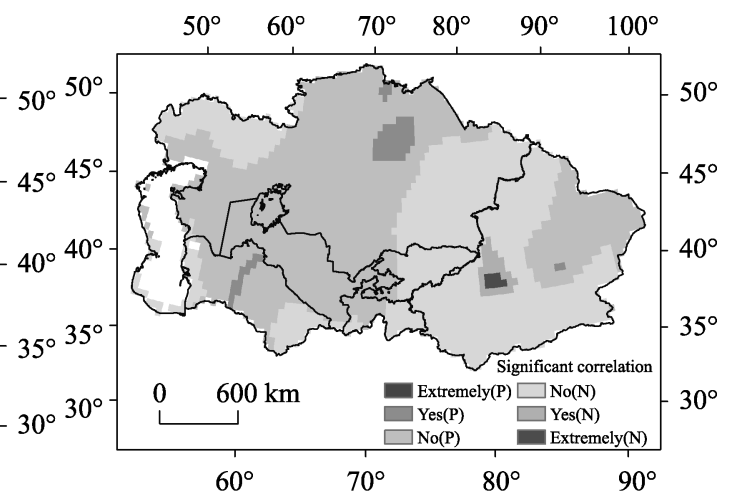

(b) Results of significance test

Figure 6 Response relationship between TWS and temperature

In Figure 5a, the mean correlation coefficient is 0.38 , indicating low correlation between TWS and precipitation in Central Asia. The variables are positively correlated in $70.82 \%$ of the study area. There is weak positive correlation in $55.08 \%$ and moderate positive correlation in $18.72 \%$ of these areas. The east of Kazakhstan, the west of the Tianshan Mountains in Xinjiang and the northwest of the Tarim Basin are the main regions showing a moderate positive correlation. Mostly, there are weakly negative correlations between TWS and precipitation.

The test results in Figure 5b indicate that TWS is significantly and positively correlated with precipitation mainly in mountainous areas and their piedmont zones in eastern Kazakhstan and western Tianshan of Xinjiang and the basin in front of it. The areas of significant and positive correlation account for about 5.92\% of Central Asia. In the eastern part of Kazakhstan, higher elevations result in more rainfall, thus precipitation has become the decisive factor for TWSC. Figures 3 and 4a show that TWS in piedmont areas is recharged by precipitations in mountains. The rainfall in the Altai Mountains significantly increased while TWS in the Balkhash Lake Basin most significantly increased. To the northeast of the Aral Sea, a significantly negative correlation was found between TWS and precipitation in the Turgay Valley, which makes up $1.01 \%$ of Central Asia. In this area, TWS decreased even with more precipitation and less evapotranspiration. Human activities may explain the phenomenon observed. 
Overall, TWS is weakly correlated with temperature and the mean correlation coefficient is 0.15 . Figure 6 a shows that the areas where they are positively correlated account for about $57.42 \%$ of Central Asia. For these areas, 62.56\% showed weakly positive correlation and only $11.31 \%$ showed a moderate positive correlation, mostly in west-central Turkmenistan and the north of Kazakhstan. The negatively correlated area covers $42.58 \%$ of Central Asia, with weak correlation occupying $62.67 \%$. In western Tianshan of Xinjiang and its southern slope, it makes up $6.9 \%$ of the area where TWS is negatively correlated with temperature, the correlation is moderate. Figure $6 \mathrm{~b}$ indicates that the regions where TWS and temperature are significantly correlated are scattered and only account for $3.78 \%$ of Central Asia.

Precipitation and TWS reached a maximum almost at the same time, but peak temperature lagged peak TWS by about three months. When the temperature data time series was moved forward by three months, the mean correlation coefficient between TWS and temperature was 0.78 , which represents a high correlation. This is because the precipitation can directly and quickly affect TWS, while the influence of temperature on TWS has to get through evapotranspiration in Central Asia.

\subsection{Relationship between vegetation change and TWSC in Central Asia}

To investigate the influence of vegetation change on TWSC, the changing trend of vegetation index and the correlation between evapotranspiration and TWSC were analyzed.

\subsubsection{Effects of vegetation change on TWS}

Using the aforementioned methods to analyze the changing trend and correlation, the relationship between vegetation index and TWS was analyzed. The results are shown in Figures 7 and 8.

Figure 7 shows that, in the study area, the NDVI is generally higher in the east and lower in the west from 2003 to 2013. The areas where the NDVI is higher are mainly distributed over the east of Kazakhstan, Kyrgyzstan, Tajikistan, Turkmenistan and Xinjiang, China. These areas make up 50.09\% of Central Asia, however NDVI increased by less than $10 \%$ in $59.9 \%$ of these areas. In the Pamirs, the Tianshan and the Kunlun mountains of Xinjiang, the NDVI showed an obvious increase. On the other hand, the NDVI decreased in $49.91 \%$ of Central Asia, mainly on the east coast of the Caspian Sea, the areas surrounding the Aral Sea, and the deserts in five countries of southeast Central Asia.

In Figure 8a, TWS and vegetation index are weakly correlated, with a mean correlation coefficient of 0.14 . The variables are positively correlated in $74.7 \%$ of the study area. The correlation is moderate or high in $30.49 \%$ of the aforementioned areas, mostly on the east coast of the Caspian Sea, the areas surrounding the Aral Sea and in southeastern Xinjiang. The regions where there is negative correlation between TWS and vegetation index cover $25.3 \%$ of Central Asia, of which $67.51 \%$ are weakly correlated. Most of the areas with moderate or high correlation are in the Pamirs, and the middle Tianshan of Xinjiang, which occupy $13.56 \%$ of the zones with negative correlation. From Figure 8 b, in $13.35 \%$ of the research areas, TWS is significantly or extremely significantly correlated with the vegetation index. These areas are mostly located in the desert regions between the Caspian Sea and Aral Sea. The effects of water on vegetation variations are most remarkable in deserts.

After shifting the NDVI data time series forward by two months, the correlation coefficient between TWSC and NDVI is up to 0.71 , namely, a moderate correlation. This shows 


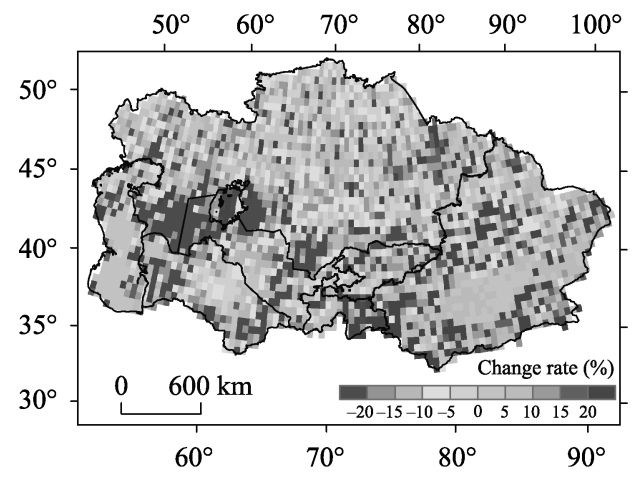

(a) Change rate

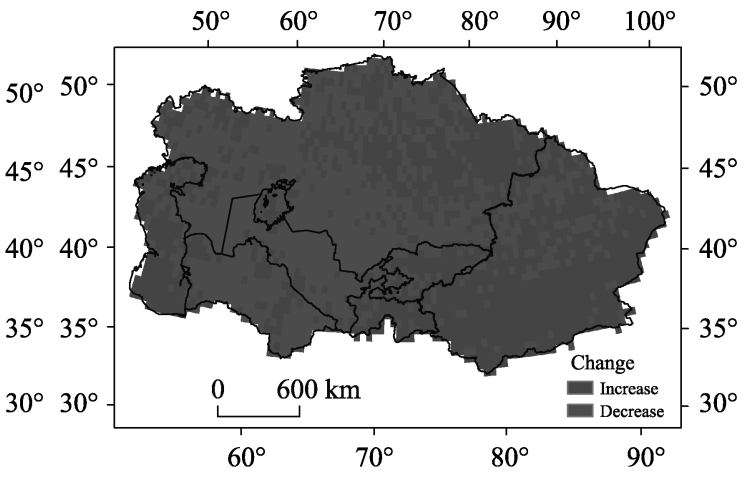

(b) Change distribution

Figure 7 Spatial variations of vegetation index (NDVI)

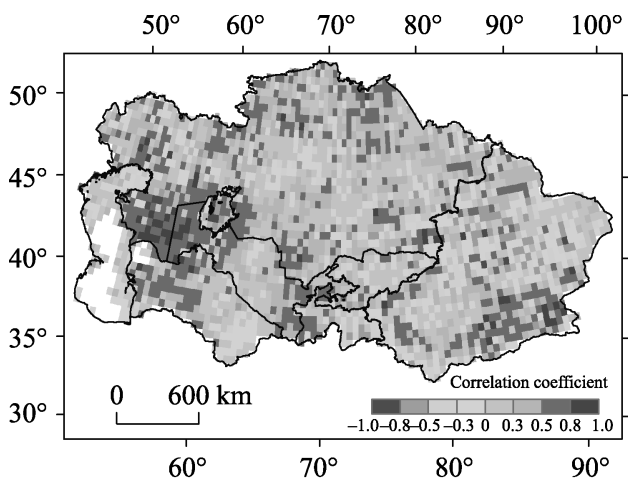

(a) Correlation coefficients

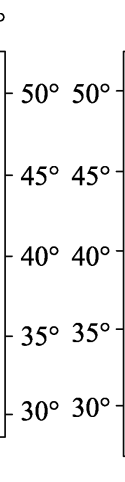

(1)

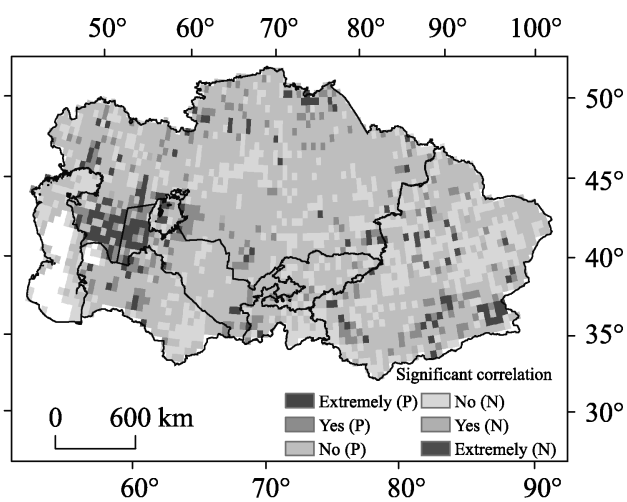

(b) Results of significance test

Figure 8 Response relationship between TWS and vegetation

that vegetation growth lags behind TWSC by about two months.

\subsubsection{Effects of evapotranspiration on TWS}

In this section, the methods used to analyze the impacts of climate change on TWS were used to investigate the spatial variations of evapotranspiration (Figure 9) and the relationship with TWS (Figure 10). Evapotranspiration in areas without any vegetation coverage was not calculated for MOD16A2 products, and its value was set as null in water, desert and the Gobi area.

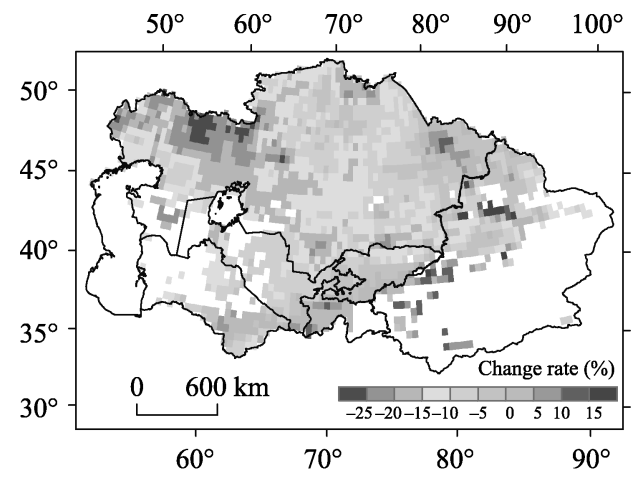

(a) Change rate

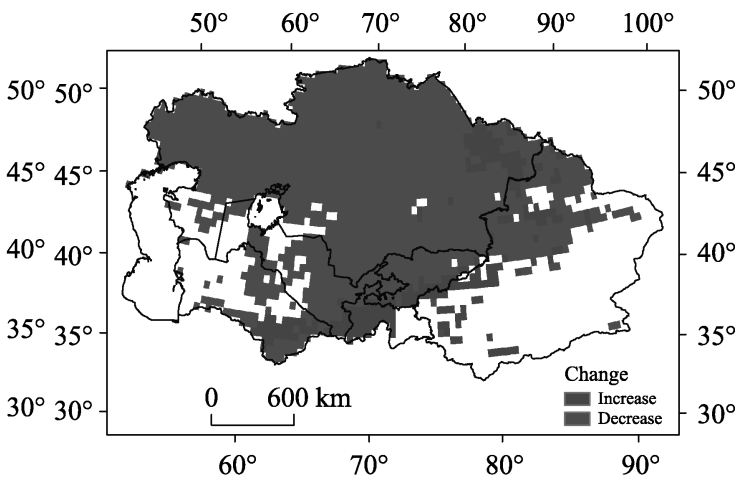

(b) Change distribution

Figure 9 Spatial variations of evapotranspiration 
Figure 9 shows an increasing trend in the evapotranspiration in only $12.07 \%$ of areas (mainly the east and southeast) from 2003 to $2013.62 .33 \%$ of areas have trends lower than $5 \%$. The areas with decreasing trends account for $87.93 \%$ of Central Asia. The reduction rates are lower than $15 \%$ in $66.11 \%$ of these areas, and greater than $20 \%$ in $8.31 \%$ of these areas. The main regions of significantly decreased evapotranspiration are the Turgay Plateau and northwest of the Plateau.

The correlations between TWS and evapotranspiration are positive in $90.69 \%$ of Central Asia (Figure 10a). Among those areas, 51.55\% show moderate or high correlation, mostly in the northern Turgay Plateau and to the west of it. However, in $9.31 \%$ of areas, mainly the Balkhash Lake Basin and desert areas of southern Central Asia, the two variables are negatively correlated. Some $73.26 \%$ of negative correlations is weak.

Figure $10 \mathrm{~b}$ shows significant or extremely significant correlations between TWS and evapotranspiration in $31.87 \%$ of the study area, mainly in the grassland of northwestern Kazakhstan and mountainous areas.

Even in conditions of decreased evapotranspiration, TWS shows a declining trend in mountainous regions, the Turgay Plateau and to its west. Reduced precipitation plays a leading role. Decreasing evapotranspiration with increasing temperature in this area is consistent with the "evaporation paradox" (Brutsaert and Parlange, 1998). TWS in plains in northern Kazakhstan decreases with reduced rainfall and evapotranspiration. The increased surface area of arable land may be the main factor explaining this relationship.

\subsection{Effects of human activities on TWSC}

LUCC was used as an index to reflect human activities. The raw data is acquired from MCD12Q1 data, processed by MRT. According to the Plant Functional Type classification system, determined by a supervised decision tree classification method, 13 types of land use are identified in Central Asia. Figure 11 shows the land use map of the study area in 2003. After summing up the area of each type between 2003 and 2013, the correlation coefficients between TWS and the area of each type were computed. The percentage of land use types in 2003 and the correlation coefficients are shown in Table 2.

As shown in the land use map (Figure 11), grassland makes up 47.37\% of Central Asia, mostly distributed in Kazakhstan, Kyrgyzstan and northwestern Xinjiang, China. The area of bare land is only second to the grassland area, with a percentage of $29.44 \%$, mainly covering the desert of southern Central Asia and Xinjiang. The Caspian Sea is the largest water body, accounting for $8.05 \%$ of the study area. The shrub land and the cereal crops that are mainly distributed in northern Kazakhstan cover $6.39 \%$ and $6.10 \%$ of the area. Other land use types cover less than $1 \%$.

Table 2 shows the highest land cover changes from 2003 to 2013 in grassland and shrub land, affecting areas of $8.36 \times 10^{4} \mathrm{~km}^{2}$ and $-8.19 \times 10^{4} \mathrm{~km}^{2}$, respectively. But we found low correlations between LUCC and TWS, with correlation coefficients of -0.36 and 0.37 , respectively. Areas of water, evergreen needle-leaf forest, cereal and broad-leaf crops changed by more than $2 \times 10^{4} \mathrm{~km}^{2}$, with correlation coefficients with TWS greater than 0.5 , namely moderate correlations. The other types of land use changed a little, and the areas of forest are moderately correlated with TWS. In summary, TWS is negatively associated with land use types whose areas increased and positively associated with the area decrease of land use 


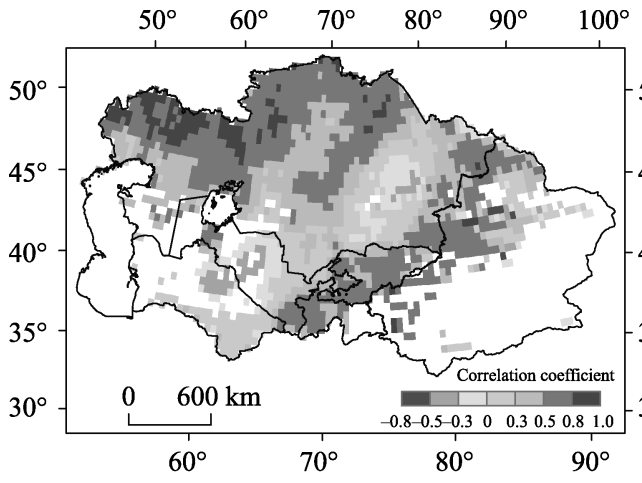

(a) Correlation coefficients

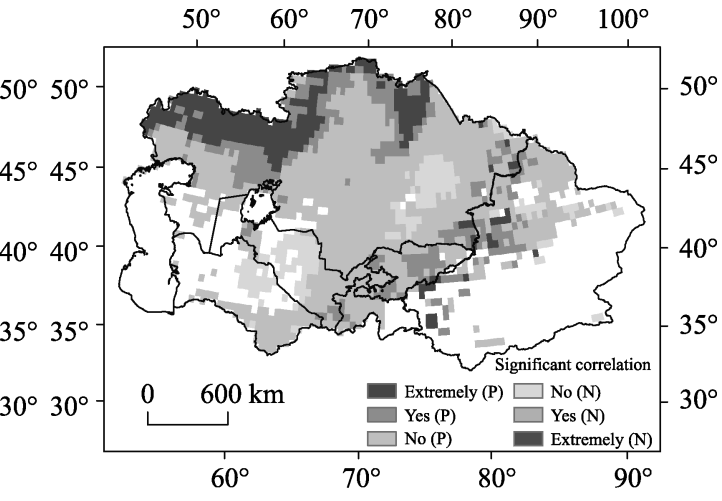

(b) Results of significance test

Figure 10 Response relationship between TWS and evapotranspiration

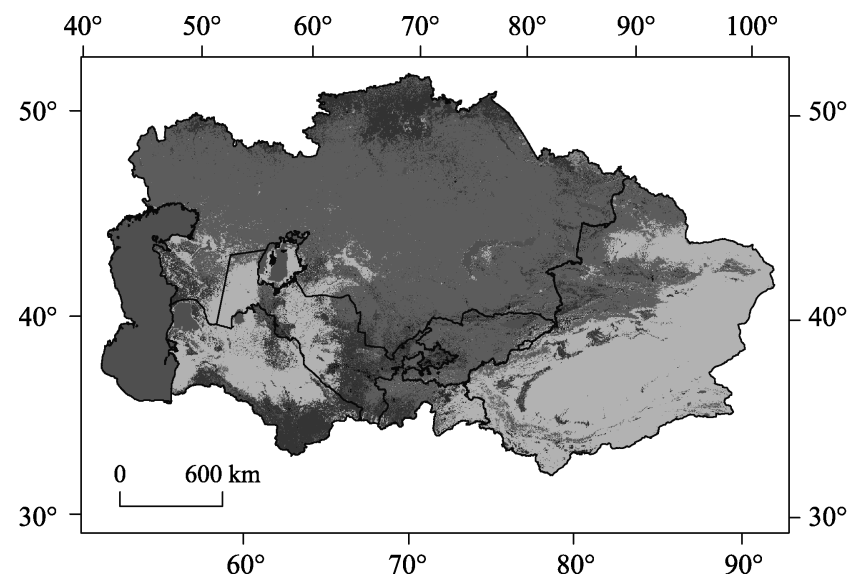

Land type (2003)

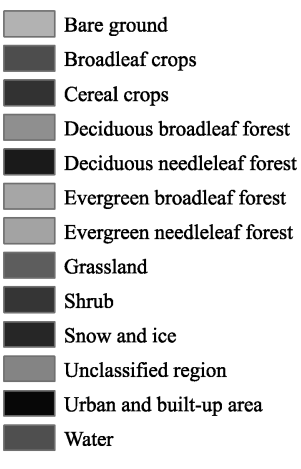

Figure 11 Land use map of Central Asia in 2003

Table 2 LUCC of Central Asia and correlation coefficients with TWS

\begin{tabular}{lccc}
\hline \multicolumn{1}{c}{ Land use type } & Percentage $(\%)$ & Changed area $\left(\times 10^{4} \mathrm{~km}^{2}\right)$ & Correlation coefficients \\
\hline Water & 8.05 & -2.20 & 0.81 \\
Evergreen needle-leaf forest & 0.21 & 2.49 & -0.76 \\
Evergreen broad-leaf forest & 0.02 & -0.06 & 0.56 \\
Deciduous needle-leaf forest & 0.05 & -0.22 & 0.75 \\
Deciduous broad-leaf forest & 0.17 & 0.25 & -0.62 \\
Shrub land & 6.39 & -8.19 & 0.37 \\
Grassland & 47.37 & 8.36 & -0.36 \\
Cereal crops & 6.10 & -5.44 & 0.55 \\
Broad-leaf crops & 1.08 & 2.32 & -0.58 \\
Urban and built-up area & 0.34 & 0.0005 & -0.50 \\
Snow and ice & 0.70 & 1.23 & -0.27 \\
Bare land & 29.44 & 1.66 & -0.15 \\
Unclassified region & 0.09 & -0.19 & 0.40 \\
\hline
\end{tabular}


types. Therefore, an analysis of correlations between TWS and land use only considering the area change is not sufficient, and the impacts of human activities on TWSC should be the focus of further research.

\section{Conclusions}

Based on the slope and Pearson correlation analysis methods, the temporal and spatial variations of TWS were analyzed using GRACE data from 2003 to 2013. The influence of climate change, evapotranspiration and human activities on TWSC in time and space were discussed, using remote sensing data including climate data, evapotranspiration, vegetation index and land use. The conclusions are as follows:

From 2003 to 2013, TWS in Central Asia increased first and then decreased with time, the volume of decreased TWS totaling about $2915.6 \times 10^{8} \mathrm{~m}^{3}$. In about $77 \%$ of Central Asia, TWS showed a decreasing trend from 2003 to 2013. The trend is more pronounced in middle-altitude regions of western and middle Central Asia and parts of the Tianshan Mountains in Xinjiang. The change rates are less than $100 \%$ over $46.4 \%$ of the areas where TWS increased. TWS significantly increased in the middle-altitude regions of the Kazakhstan hills and Tarim Basin.

The mean correlation coefficient between TWS and precipitation is 0.38 . These variables, either significantly or extremely significantly, are positively correlated in mountain and piedmont regions, which account for $5.91 \%$ of Central Asia. The rainfall in mountainous areas is the main supply source of TWS in piedmont regions, while water storage in the Turgay Valley may be mainly affected by human activities. Air temperature has a weak effect on TWS with a mean correlation coefficient of 0.15 , with significant correlation coefficients in only $3.78 \%$ of the study area. There is a three-month lag between temperature change and TWSC.

The mean correlation coefficient between TWS and NDVI is 0.14 overall. Correlations are positive and significant or extremely significant in $13.35 \%$ of the study area, mainly in the desert between the Caspian Sea and Aral Sea. In this region, the effect of water on vegetation is remarkable, and the response of NDVI to TWS lags by two months.

Significant or highly significant positive correlation was found between TWS and evapotranspiration in $31.87 \%$ of Central Asia, mostly the mountainous areas and northwestern Kazakhstan. The decrease of regional TWS is related to the decrease in precipitation rather than evaporation. Even in conditions of precipitation increase and evapotranspiration decrease, TWS still decreases in the north of Kazakhstan. The main reason may be the increase in farmland area.

The effects of land use and land cover change on TWS are analyzed in this paper, but this lacks the consideration of a response mechanism between these variables. Exploring how land use changes affect TWS will be the focus of a future study.

\section{Acknowledgments}

The authors would like to thank the anonymous reviewers for suggesting improvements to the manuscript. We also thank the help of International Science Editing.

\section{References}

Aizen V B, Aizen E M, Melack J M et al., 1997. Climatic and hydrologic changes in the Tien Shan, Central Asia. 
Journal of Climate, 10(6): 1393-1404.

Alley W M, Healy R W, La B J W et al., 2002. Flow and storage in groundwater systems. Science, 296(5575): 1985-1990.

Awange J L, Forootan E, Kuhn M et al., 2014. Water storage changes and climate variability within the Nile Basin between 2002 and 2011. Advances in Water Resources, 73: 1-15.

Bernauer T, Siegfried T, 2012. Climate change and international water conflict in Central Asia. Journal of Peace Research, 49(1): 227-239.

Brutsaert W, Parlange M B, 1998. Hydrologic cycle explains the evaporation paradox. Nature, 396(6706): 30.

Cao Y, Nan Z, Cheng G, 2015. GRACE gravity satellite observations of terrestrial water storage changes for drought characterization in the arid land of northwestern China. Remote Sensing, 7(1): 1021-1047.

Cayan D R, 1996. Inter-annual climate variability and snowpack in the western United States. Journal of Climate, 9(5): 928-948.

Chen F H, Huang W, Jin L Y et al., 2011. Spatiotemporal precipitation variations in the arid Central Asia in the context of global warming. Science China Earth Sciences, 54(12): 1812-1821.

Chen J L, Wilson C R, Tapley B D et al., 2009. 2005 drought event in the Amazon River basin as measured by GRACE and estimated by climate models. Journal of Geophysical Research Atmospheres, 114(B5): 3093-3107.

Chen X, 2008. Land Use/Cover Change in Arid Areas in China. Beijing: Science Press, 180-201. (in Chinese)

Chen X, Bai J, Li X et al., 2013. Changes in land use/land cover and ecosystem services in Central Asia during 1990-2009. Current Opinion in Environmental Sustainability, 5(1): 116-127.

Chen Y, Li Z, Fan Y et al., 2015. Progress and prospects of climate change impacts on hydrology in the arid region of Northwest China. Environmental Research, 139: 11-19.

De K M, Henebry G M, Owsley B C et al., 2015. Using multiple remote sensing perspectives to identify and attribute land surface dynamics in Central Asia 2001-2013. Remote Sensing of Environment, 170: 48-61.

De P E, 2008. ICARDA regional GIS datasets for Central Asia: Explanatory notes. GIS Unit Technical Bulletin. International Center for Agricultural Research in the Dry Areas (ICARDA), Aleppo.

Deng H, Chen Y, 2016. Influences of recent climate change and human activities on water storage variations in Central Asia. Journal of Hydrology, 544: 46-57.

Dijk A I J M V, Peña-Arancibia J L, Wood E F et al., 2013. Global analysis of seasonal streamflow predictability using an ensemble prediction system and observations from 6192 small catchments worldwide. Water Resources Research, 49(5): 2729-2746.

Frappart F, Ramillien G, Ronchail J, 2013. Changes in terrestrial water storage versus, rainfall and discharges in the Amazon basin. International Journal of Climatology, 33(14): 3029-3046.

Gao H, Wood E F, Drusch M et al., 2004. Using a microwave emission model to estimate soil moisture from ESTAR observations during SGP99. Journal of Hydrometeorology, 5(1): 49-63.

Han S C, Yeo I Y, Alsdorf D et al., 2010. Movement of Amazon surface water from time-variable satellite gravity measurements and implications for water cycle parameters in land surface models. Geochemistry Geophysics Geosystems, 11(9): 1-20.

Hu Z, Zhang C, Hu Q et al., 2014. Temperature changes in Central Asia from 1979 to 2011 based on multiple datasets. Journal of Climate, 27(3): 1143-1167.

Huang Y, Salama M, Krol M S et al., 2015. Estimation of human-induced changes in terrestrial water storage through integration of GRACE satellite detection and hydrological modeling: A case study of the Yangtze River basin. Water Resources Research, 51(10): 8494-8516.

Immerzeel W W, Beek L P H V, Bierkens M F P, 2010. Climate change will affect the Asian water towers. Science, 328(5984): 1382-1385.

Khandu, Forootan E, Schumacher M et al., 2016. Exploring the influence of precipitation extremes and human water use on total water storage (TWS) changes in the Ganges-Brahmaputra-Meghna River Basin. Water Resources Research, 52(3): 2240-2258.

Lettenmaier D P, Famiglietti J S, 2006. Hydrology: Water from on high. Nature, 444(444): 562-563.

Lioubimtseva E, Henebry G M, 2009. Climate and environmental change in arid Central Asia: Impacts, vulnerability, and adaptations. Journal of Arid Environments, 73(11): 963-977.

Long D, Longuevergne L, Scanlon B R, 2015. Global analysis of approaches for deriving total water storage changes from GRACE satellites. Water Resources Research, 51(4): 2574-2594.

Long D, Shen Y, Sun A et al., 2014. Drought and flood monitoring for a large karst plateau in Southwest China using extended GRACE data. Remote Sensing of Environment, 155(1): 145-160. 
Luthcke S B, Zwally H J, Abdalati W et al., 2006. Recent Greenland ice mass loss by drainage system from satellite gravity observations. Science, 314(5803): 1286-1289.

Matsuo K, Heki K, 2010. Time-variable ice loss in Asian high mountains from satellite gravimetry. Earth and Planetary Science Letters, 290(1/2): 30-36.

Mohamed A, Mohamed S, John W et al., 2011. Integration of GRACE (Gravity Recovery and Climate Experiment) data with traditional data sets for a better understanding of the time-dependent water partitioning African watersheds. Geology, 39(5): 479-482.

Njoku E G, Jackson T J, Lakshmi V et al., 2003. Soil moisture retrieval from AMSR-E. IEEE Transactions on Geoscience \& Remote Sensing, 41(2): 215-229.

Qin B Q, 1999. A preliminary investigation of lake evolution in 20-century in Inland Mainland Asia with relation to the global warming. Journal of Lake Science, 11(1): 11-19. (in Chinese)

Ramillien G, Frappart F, Cazenave A et al., 2005. Time variations of land water storage from an inversion of 2 years of GRACE geoids. Earth \& Planetary Science Letters, 235(1/2): 283-301.

Robock A, Vinnikov K Y, Srinivasan G et al., 2000. The global soil moisture data bank. Bulletin of the American Meteorological Society, 81(6): 1281-1300.

Rodell M, Velicogna I, Famiglietti J S, 2009. Satellite-based estimates of groundwater depletion in India. Nature, 460(7258): 999-1003.

Schmidt R, Schwintzer P, Flechtner F et al., 2006. GRACE observations of changes in continental water storage. Global \& Planetary Change, 50(1): 112-126.

Serreze M C, Clark M P, Armstrong R L et al., 1999. Characteristics of the western United States snowpack from snowpack telemetry (SNOTEL) data. Water Resources Research, 35(7): 2145-2160.

Siegfried T, Bernauer T, Guiennet R et al., 2012. Will climate change exacerbate water stress in Central Asia? Climatic Change, 112(3): 1-19.

Singh A, Seitz F, Schwatke C, 2012. Inter-annual water storage changes in the Aral Sea from multi-mission satellite altimetry, optical remote sensing, and GRACE satellite gravimetry. Remote Sensing of Environment, 123(4): 187-195.

Sorg A, Bolch T, Stoffel M et al., 2012. Climate change impacts on glaciers and runoff in Tien Shan (Central Asia). Nature Climate Change, 2(10): 725-731.

Suo Y, Wang Z, Liu C et al., 2009. Relationship between NDVI and precipitation and temperature in middle Asia during 1982-2002. Resources Science, 28(12): 1145-1152.

Syed T H, Famiglietti J S, Rodell M et al., 2008. Analysis of terrestrial water storage changes from GRACE and GLDAS. Water Resources Research, 44(2): 339-356.

Tangdamrongsub N, Hwang C, Kao Y C, 2011. Water storage loss in Central and South Asia from GRACE satellite gravity: Correlations with climate data. Natural Hazards, 59(2): 749-769.

Tapley B D, Bettadpur S, Ries J C et al., 2004. GRACE measurements of mass variability in the Earth system. Science, 305(5683): 503-505.

Velicogna I, Wahr J, 2006. Measurements of time-variable gravity show mass loss in Antarctica. Science, 311(5768): 1745-1756.

Wahr J, Molenaar M, Bryan F, 1998. Time variability of the earth's gravity field: Hydrological and oceanic effects and their possible detection using grace. Journal of Geophysical Research Solid Earth, 103(B12): 30205-30230.

Wahr J, Swenson S, Zlotnicki V, 2004. Time-variable gravity from GRACE: First results. Geophysical Research Letter, 31(11): 293-317.

Wang J S, Chen F, Jin L et al., 2010. Characteristics of the dry/wet trend over arid Central Asia over the past 100 years. Climate Research, 41(1): 51-59.

Yang P, Chen Y, 2015. An analysis of terrestrial water storage variations from GRACE and GLDAS: The Tianshan Mountains and its adjacent areas, Central Asia. Quaternary International, 358(11): 106-112.

Yang T, Wang C, Chen Y et al., 2015. Climate change and water storage variability over an arid endorheic region. Journal of Hydrology, 529: 330-339.

Yang T, Wang C, Yu Z et al., 2013. Characterization of spatio-temporal patterns for various GRACE- and GLDAS-born estimates for changes of global terrestrial water storage. Global and Planetary Change, 109(4): 30-37.

Zhou H, Deng Z, Xia Y et al., 2016. A new sampling method in particle filter based on Pearson correlation coefficient. Neurocomputing, 216: 208-215. 